\title{
CIBERAULA E NATIVOS DIGITAIS: UMA EXPERIÊNCIA DE EDUCAÇÃO A DISTÂNCIA NA EDUCAÇÃO BÁSICA
}

\author{
Aloirmar José da Silva* \\ José Washington de Morais Medeiros ${ }^{* *}$ \\ Marckson Roberto de Sousa ${ }^{* * *}$
}

\begin{abstract}
Resumo: O advento das tecnologias digitais da informação e comunicação, aliadas ao uso da Internet, tem provocado mudanças significativas na contemporaneidade, dimensionadas pelas características da sociedade em rede, e com novas perspectivas para a educação. Nesse horizonte, este estudo analisou a concepção dos estudantes do ensino fundamental (nativos digitais) acerca da utilização da educação a distância como complementação da aprendizagem na educação básica. Trata-se de uma pesquisa com abordagem quantiqualitativa, do tipo exploratória, com estudantes do $7^{\circ}$ ano do ensino fundamental, do Colégio Marista Pio X, em João Pessoa-PB, que participaram do Curso de História e Cultura Afro-brasileira e Indígena, na modalidade a distância. Os resultados apontam que a experiência foi significativa para os estudantes, tendo em vista que contribuiu para o êxito do processo educativo empreendido pela escola, notadamente nos resultados obtidos pelos estudantes e na avaliação que eles fazem da experiência.
\end{abstract}

Palavras-chave: Educação a distância. Educação básica. Nativos digitais.

\section{Introdução}

A sociedade contemporânea é marcada por um cenário amplo e complexo, que combina desenvolvimento com desigualdade, tecnologia com exclusão. Esse cenário institui a sociedade global, aberta e em constante movimento, em que as tecnologias digitais da informação e comunicação, aliadas ao uso da internet, modificam a noção de tempo/espaço e exigem dos sujeitos sociais adaptabilidade a novos contextos de aprendizagem e de trabalho, o que demanda novas competências, habilidades e atitudes.

\footnotetext{
* Doutorando em Educação; Mestre em Gestão nas Organizações Aprendentes pela Universidade Federal da Paraíba. Diretor do Colégio Marista Nossa Senhora da Penha, Vila Velha-ES. E-mail: aloirmar@hotmail.com

${ }^{* *}$ Doutor em Educação. Professor do Mestrado Profissional em Educação Profissional e Tecnológica (ProfEPT) do Instituto Federal de Educação, Ciência e Tecnologia da Paraíba - IFPB. Professor colaborador do Programa de Pós-Graduação Gestão em Organizações Aprendentes (PPGOA) da Universidade Federal da Paraíba - UFPB. E-mail: washi_med@yahoo.com.br

*** Doutor em Engenharia Elétrica. Professor do Programa de Pós-graduação em Ciência da Informação (PPGCI), e do Programa de Pós-Graduação Gestão em Organizações Aprendentes (PPGOA) da Universidade Federal da Paraíba - UFPB. E-mail: marckson.mpgoa@gmail.com
} 
Nessa lógica societária, o ciberespaço, a informação e a aprendizagem, atinentes à cultura digital, atravessam e afetam as instituições, de maneira especial, a família, a escola e os ambientes de trabalho, pois "a apropriação da capacidade de interconexão por redes sociais de todos os tipos levou à formação de comunidades online que reinventaram a sociedade e, nesse processo, expandiram espetacularmente a interconexão dos computadores, em seu alcance e em seus usos" (CASTELLS, 2003, p.53).

Essa realidade interconectada é responsável por alterações de conduta, de costumes e de valores nas relações entre os indivíduos e na forma como eles se comunicam e conferem significados às coisas no mundo. Tais alterações podem ser mais intensas e conflitantes, porque, conforme Oliveira (2010), é a primeira vez que gerações diferentes, como os nativos digitais, convivem na mesma sociedade, seja em espaços de aprendizagem, seja no trabalho.

Com base em Palfrey e Gasser (2011), entende-se por nativos digitais a geração que nasceu e está crescendo no tempo das interconexões da sociedade em rede, "zapeando" nas infovias da cultura digital, o que promove uma relação umbilical com a condição de estar sempre online. Formas de comunicação, de sociabilidade, de afetividade, de aprendizagem etc. estão intimamente relacionadas com o uso da tecnologia digital, o que, muitas vezes, causa impactos em instituições como a família e a escola, visto que os nativos digitais apresentam propensão cultural à hibridização entre homem e máquina sem precedentes, similar ao que Oliveira (2017) denomina de "práticas ciborguianas", ou seja, marcas da simbiose cultural tecnohumana.

De acordo com Silva (2013, p.18), "no campo educacional, as tecnologias, a grande variedade de mídias digitais e as redes de comunicação estão contribuindo muito para que haja profundas alterações tanto na modalidade presencial quanto na educação a distância”, o que permite dizer que os desafios da educação a distância (EaD) são equivalentes aos desafios do sistema educacional em sua totalidade. No entanto, a experiência de EaD na educação básica, ou seja, com crianças e adolescentes, ainda é pouco explorada no Brasil.

Neste artigo, analisou-se a concepção de estudantes do ensino fundamental (nativos digitais) acerca da utilização da educação a distância como complementação da aprendizagem na educação básica. Essa experiência foi realizada no Colégio Marista Pio X, em João Pessoa - PB, e partiu do seguinte questionamento: como estudantes do ensino fundamental concebem a EaD no processo de ensino-aprendizagem a partir da experiência vivida? 


\section{Da geração "Y" aos nativos digitais}

De acordo com Oliveira (2010), nos 1980 e 1990, surgiu a geração Y, cujo nome provém do período em que a União Soviética tinha forte poder sobre os países comunistas e chegou a definir que os bebês nascidos nesses anos deveriam receber nomes iniciados com a letra Y. As principais características dessa geração podem ser sintetizadas como a necessidade constante de reconhecimento, a opção por padrões informais e flexíveis, a individualidade como forma de expressão e a busca intensa por ampliar a rede de relacionamentos. Essas particularidades vêm provocando mudanças nas relações sociais, de maneira significativa, na educação, na família e no ambiente de trabalho.

A geração Y é extremamente informada, mas detém certo componente de alienação. Como nasceu de famílias estruturadas em modelos mais flexíveis, conta com múltiplas influências familiares e, no dia a dia, aprendeu a lidar não apenas com a ausência do pai, mas também com a da mãe. Essa geração tem facilidade de apreender outras línguas e interesse em estudá-las e é muito influenciada pela tecnologia. Nesse contexto, o uso do videogame é uma marca registrada. A popularização da internet, com a possibilidade de comunicação instantânea e sem fronteiras, bem como acesso a todo tipo de conteúdo, o que torna a informação irrestrita e ilimitada, credenciou a geração Y como a geração da tecnologia (OLIVEIRA, 2010).

Na visão de Palfrey e de Gasser (2011), o conceito e as características da geração Y equivalem ao que chamaram de "nativos digitais" ou geração Z, que zarpam, zapeiam e navegam o tempo todo na internet e estão constantemente conectados. Eles nasceram na era digital, começaram a aprender na linguagem digital e não conheceram nada além de uma vida conectada a outro e ao mundo dos bits. Para os autores, os nativos digitais são naturais na maneira de levar a vida, tanto nos espaços online quanto ofline, gastam grande quantidade de tempo usando tecnologias digitais, costumam fazer várias coisas ao mesmo tempo, e suas formas de se expressar e de se relacionar misturam o humano com o técnico e causam uma verdadeira metamorfose nas relações humanas.

Guardadas as devidas proporções e considerados os abismos criados pela desigualdade social que impera no Brasil e o conflito entre as gerações, é fato que a maioria dos estudantes de educação básica da atualidade nasceu "na nova era que está surgindo, a Era das Conexões (a partir de 2000), alavancada por toda a tecnologia proporcionada pelo crescimento dos meios de comunicação, sobretudo de telefonia e internet” (OLIVEIRA, 2010, p.25). A presença desses estudantes, com seus vários modos de ser, desafia os fundamentos da 
educação e as instituições de ensino (educação básica) a repensarem suas tradicionais propostas curriculares e a concepção de tempo e de espaço presentes no planejamento, na gestão, nas propostas e nas ações pedagógicas dos processos educativos.

É preciso deixar claro que não se trata de usar as tecnologias a qualquer custo ou de qualquer jeito, "mas de acompanhar, consciente e deliberadamente, uma mudança de civilização que questiona profundamente as formas institucionais, as mentalidades e a cultura dos sistemas educacionais tradicionais e, sobretudo, os papéis de professor e do aluno" (LÉVY, 2010, p. 174). Trata-se de reinventar a prática educativa por meio da cibercultura, substituindo o velho padrão das hierarquias dogmáticas do saber por um princípio dialógicocooperativo, que parte de todos para todos e promove a aprendizagem coletiva.

Cabe, aqui, a distinção feita por Sodré (2012), para quem as práticas juvenis que se multiplicam em torno do bios virtual não decorrem da noção clássica de diferença natural entre as gerações, mas da coincidência entre as transformações do mundo do trabalho e as dinâmicas de urbanidade que os dispositivos tecnológicos são capazes de provocar. Essa distinção é importante, não para originar uma espécie de "demonização" das tecnologias digitais ou da internet, mas para promover a reflexão crítica do emprego desses dispositivos e do jogo de interesses e de intencionalidades que sustentam e impulsionam sua utilização, pois, segundo Lévy (2010, p.24), "por trás das técnicas, agem e reagem ideias, projetos sociais, utopias, interesses econômicos, estratégias de poder e toda gama de jogos dos homens em sociedade".

\section{Educação a Distância (EaD): aspectos conceituais}

Segundo Alves (2009), Bizzo (2009) e Mugnol (2009), no Brasil, a história da EaD é marcada por momentos de sucesso e de estagnação, e dividida em três fases: uma inicial, uma intermediária e outra mais moderna: a) a fase inicial começou com ações isoladas no seio da República, e o marco de referência foi a instalação das Escolas Internacionais em 1904; b) a fase intermediária corresponde ao uso da televisão para fins educacionais, nas décadas de 1960 e 1970; embora importante, a fase foi marcada por certa estagnação, tendo em vista o regime militar e a censura imposta aos meios de comunicação social; c) a fase moderna, marcada pela chegada dos computadores no Brasil, no final da década de 1970, e sua instalação em algumas universidades para fins de educação. Posteriormente, os computadores foram se popularizando, e com a chegada da Internet nos grandes centros urbanos, o ensino a distância foi se propagando e se consolidando pelo país. Nessa fase, três organizações 


\section{\#tear}

merecem destaque: a Associação Brasileira de Telecomunicação, criada em 1971, que, mais tarde, organizou os Seminários Brasileiros de Tecnologia Educacional e editou a Revista Tecnologia Educacional, que permanecem até os dias de hoje; o Instituto de Pesquisa e Administração da Educação (IPAE), responsável pelos primeiros Encontros Nacionais e pelos Congressos Brasileiros de EaD; e a Associação Brasileira de EAD (ABED), cujo mais expressivo papel foi o de sediar a 22 $2^{\text {a }}$ Conferência Mundial de Educação Aberta e a Distância do ICDE.

No que tange aos aspectos conceituais, a EaD tem características específicas que a diferenciam do ensino presencial quanto ao método, aos meios e às estratégias usadas para disseminar o conhecimento. Trata-se de uma modalidade de educação em que o processo de ensino-aprendizagem é desenvolvido "sem que alunos e professores estejam presentes no mesmo lugar, na mesma hora" (ABED, 2006, p.1). Nas últimas décadas, esse processo acontece, quase sempre, mediado pelas tecnologias digitais da informação e comunicação, com estudantes e professores separados em relação ao espaço e ao tempo, mas conectados por meio dos dispositivos de rede e do conteúdo didático colocado à disposição.

Portanto, a EaD pode ser uma modalidade de educação bastante efetiva para o estágio atual da sociedade globalizada e tecnológica, porquanto traz, em si, uma nova compreensão de tempo e de espaço, elementos-chave para se compreenderem a cibercultura e o ciberespaço. Para Lévy (2010), o ciberespaço surgiu como uma possibilidade de validar os conhecimentos e as competências adquiridas, inclusive, fora da escola, visto que possibilita que pensemos em vastos sistemas de testes automatizados, acessíveis em qualquer momento e de qualquer lugar. Segundo ele, os sistemas de educação e formação necessitam ajustar os dispositivos e o espírito do ensino aberto a distância e reconhecer as experiências adquiridas, pois as pessoas não aprendem só na escola ou nos espaços formais de educação.

Sendo assim, a EaD é uma prática educativa situada, mediatizada por materiais e meios de comunicação e baseada em uma racionalidade ética, solidária e dialógica, em que a participação, a criatividade, o compromisso e a prática de construção são elementos fundantes. Nessa perspectiva, a EaD é constituída de, pelo menos, três dimensões: a realidade social, a educação e a tecnologia. O ponto de partida é a realidade social, pois não é possível pensar na $\mathrm{EaD}$ fora de um contexto, muito menos desprovida da conjuntura econômicopolítico-social contemporânea. Quanto à educação, o horizonte da humanização, no rumo da emancipação social, deve conferir intencionalidade a qualquer processo de EaD. E a tecnologia deve ser encarada como um meio, um conjunto de mecanismos e dispositivos que 


\section{\#tear}

possibilitam a materialização do ato educativo (MAROTO, 1996; DIAS; LEITE, 2012; FICHMANN, 2012).

\section{Educação básica e educação a distância}

De acordo com o artigo 21 da Lei de Diretrizes e Bases da Educação Nacional - LDB (Lei 9.934/96), a educação escolar brasileira é composta pela educação básica, formada de três etapas - educação infantil, ensino fundamental e ensino médio; e pela educação superior. A ideia de educação básica consiste na formação essencial e necessária para o exercício da cidadania, com a aquisição de conhecimentos, competências, habilidades e atitudes. O conjunto das etapas da educação básica deve funcionar de forma articulada e totalizadora, a fim de levar o estudante a edificar sua pertença à comunidade como casa comum, e um senso de abertura e de respeito à diversidade e à solidariedade, bem como o cuidado com a vida em todas as suas dimensões (CARNEIRO, 2015; LIBÂNEO et al, 2009).

Nesse horizonte, assim se inscreve o Artigo 22 da LDB: “A educação básica tem por finalidades desenvolver o educando, assegurar-lhe a formação comum indispensável para o exercício da cidadania e fornecer-lhe meios para progredir no trabalho e em estudos posteriores" (CARNEIRO, 2015, p.298). A mesma articulação presente entre as três etapas - educação infantil, ensino fundamental e ensino médio - deve ser garantida no tripé que constitui a finalidade e deve sustentar o processo educativo na educação básica.

Em se tratando do desenvolvimento pleno do educando, deve-se levar em conta a ampliação de suas capacidades cognitivas, das operações mentais e de todas as potencialidades que são percebidas durante o percurso. Trata-se, ainda, de atender às necessidades educacionais básicas, que, para Lück (2014), estão no bojo das necessidades fisiológicas e de segurança, de pertencimento, de ser estimado e valorizado, de ser bemsucedido, de bem-estar e ordem, de tomar decisões, de resolver problemas e de realizar como ser humano.

No que diz respeito ao exercício da cidadania, na educação básica, o processo educativo deve garantir aos estudantes uma formação capaz de fazê-los compreender todos os seus direitos e deveres, bem como exercitá-los no horizonte da emancipação social. Tal processo deve ajudá-los a romper definitivamente com a concepção que reduz o cidadão a um indivíduo que vota nos diferentes pleitos eleitorais, para assumir a perspectiva da cidadania ligada ao agir individual e coletivo, na construção social e política de seu futuro, por meio de 


\section{\#tear}

instrumentos, mecanismos e práticas que possibilitem e legitimem a participação social efetiva.

O terceiro item do tripé, que sustenta a finalidade da educação básica, consiste em possibilitar a progressão no trabalho e em estudos posteriores, compreendendo o trabalho como um meio de realização humana e de transformação da realidade. Carneiro $(2015$, p.58) refere que "a escola e os sistemas de ensino precisam entrar no mundo do trabalho e introduzi-lo como categoria de inspiração do currículo se, de fato, pretendem resgatar a sala de aula como um ambiente funcional para a sociedade tecnológica em metamorfose profunda".

No que diz respeito à organização curricular, a LDB sugere um processo educativo em que a leitura transformadora de mundo esteja presente, seja ensinada e aprendida. O currículo deixa de ser "grades" e assume os contornos de "redes" de conhecimentos, aberto e em movimento, capaz de levar para o interior da escola os contextos de vida dos sujeitos, dialogando com as subjetividades contemporâneas, na perspectiva da emancipação, e não, apenas, justificando-as numa espécie de fatalismo e de conformismo intermináveis. Assume a arte e a cultura como um princípio educativo, ligadas às regionalidades e às raízes que podem congregar a diversidade a uma perspectiva dialógica, em que o diferente tem direito de ser e de existir.

A EaD é citada no artigo 32 da LDB, que trata da organização do ensino fundamental como uma das etapas da educação básica. Depois de falar do objetivo e dos aspectos que devem ser contemplados na formação do estudante, da possibilidade de desdobrá-lo em ciclos, de adotar a progressão continuada e de oficializar a língua portuguesa, encontra-se o seguinte parágrafo: "O ensino fundamental será presencial, e o ensino a distância utilizado como complementação da aprendizagem ou em situações emergenciais" (CARNEIRO, 2015, p. 373).

Há uma definição clara sobre o caráter presencial da educação básica, em que não é possível o formato semipresencial ou a distância (BIZZO, 2009). Isso pode ser justificado porque, sem contato direto, os estudantes estariam impedidos de compartilhar processos de socialização e de aprendizagem cooperativa (CARNEIRO, 2015). Desse modo, a frequência à escola não é apenas uma questão de disciplina, mas um meio de interatividade, de geração de convívio, de trabalho coletivo. Por outro lado, é possível contrapor esses argumentos com base no pensamento de Sêga (2011) e de Lévy (2010) que, ao discutir sobres as diferentes formas de interação humana e sobre o conceito de interatividade, argumentam que os meios 
virtuais modificam a forma como a presencialidade, o convívio, a interação e a ação colaborativa acontecem, mas deixam claro que só há mudança na forma, e não, na inexistência, uma vez que os modos de interagir mudam de acordo com os contextos.

Enquanto a LDB continuar com essa perspectiva para a educação básica, é preciso tomar a EaD como uma possibilidade de complementar a aprendizagem. Embora seja limitado, é um campo fecundo para a escola, pois "a adoção de estratégias de EaD amplia o papel da escola, levando-a para além dos muros e das paredes e atende ao anseio do aluno que deseja ser mais participante do seu processo de aprendizagem” (ASSUMPÇÃO, 2012, p.161). Essas estratégias enriquecem o processo educativo e sintonizam as práticas pedagógicas com as novas gerações, o que proporciona um alargamento do espaço e do tempo em que a aprendizagem acontece (SANCHO, 2010).

\section{Traçando os caminhos metodológicos da pesquisa}

Considerando o objetivo de analisar a concepção de estudantes do ensino fundamental (nativos digitais) acerca da utilização da educação a distância como complementação da aprendizagem na educação básica, foi desenvolvida uma pesquisa de campo, de abordagem quantiqualitativa, do tipo exploratória. Tal mixed-methodological foi oportuno, tendo em vista a necessidade de, sistematicamente, captar sentidos e mensurar variáveis sobre a EaD na educação básica e apresentar substratos para uma investigação mais completa sobre esse fenômeno (GERHARDT, SILVEIRA, 2009; GIL, 2014).

O campo empírico foi o Colégio Marista Pio X, em João Pessoa-PB, uma das escolas mais antigas e, do ponto de vista histórico, significativa da capital paraibana, cuja proposta pedagógica se edifica nas sinergias entre formação humana e espiritualidade, com orientação cristã (católica). A escola oferece, anualmente, o Curso de História e Cultura Afro-brasileira e Indígena aos estudantes de $7^{\circ}$ ano do Ensino Fundamental, na modalidade de EAD, como complementação curricular. A escolha dessa instituição se justifica por ser a única entre as escolas públicas e particulares, segundo consta, de João Pessoa e da Paraíba, que oferece essa modalidade de educação no ensino fundamental.

Assim, considerando o universo de 152 estudantes que cursaram o $7^{\circ}$ ano do Ensino Fundamental durante a realização desta pesquisa, foi selecionada uma amostra de 38 estudantes, ou seja, 25\% do total que participou do curso. Eles foram escolhidos de acordo com nota final obtida no Curso de $\mathrm{EaD}$, obedecendo à ordem do maior para o menor e respeitando o desejo de participar da pesquisa. 
Os dados foram coletados por meio de um questionário combinado ou misto, por causa da praticidade na análise e por promover o acesso, em menos tempo, aos informantes e mantêlos no anonimato. Segundo Gil (2014, p. 122), uma das maiores vantagens do questionário é “não expor os pesquisados à influência das opiniões e do aspecto pessoal do entrevistador". Os dados quantitativos coletados foram organizados/tabulados por meio da estatística descritiva, e os dados qualitativos foram sistematizados por meio da técnica de Análise de Conteúdo. Com base em Bardin (2011), a Análise de Conteúdo é um conjunto de procedimentos que visam salvaguardar o rigor da objetividade e da subjetividade, que são essenciais para a produção do conhecimento, em três fases: a de pré-análise, a de exploração do material e a de tratamento dos resultados.

A pré-análise versou sobre a organização do material coletado. Em seguida, houve a exploração do material preparado e a classificação do conteúdo nas seguintes categorias: Ambiente Virtual de Aprendizagem (AVA), Práticas Pedagógicas, Mediação e Aprendizagens. No último momento da análise de conteúdo, o conteúdo foi interpretado e sistematizado em categorias, com o fim de encontrar os resultados e as inferências que trouxeram respostas para o problema apontado.

\section{Apresentação e análise dos resultados da pesquisa}

\subsection{O Ambiente Virtual e o Curso de História e Cultura Afro-brasileira e Indígena}

O Colégio Marista Pio X oferece aos educandos e aos seus responsáveis, por meio da internet, uma plataforma virtual, conhecida como Ambiente de Integração. Trata-se de um software de apoio à aprendizagem (e-learning), uma distribuição do Moodle 2.6.10 (Build: 20150310) personalizada pela instituição, executado como Ambiente Virtual de Aprendizagem, com acesso restrito e monitorado através de navegadores da WEB (browsers).

De acordo com Dias e Leite (2012), o Moodle é uma plataforma aberta, livre e gratuita para a aprendizagem a distância, com diversos recursos e múltiplas atividades de interação, o que facilita a apreensão e a construção do conhecimento. Esse software está instalado em servidores próprios da Rede Marista, com segurança e privacidade. Permite a produção de páginas em que se utilizam textos, vídeos, imagens, áudios, fóruns de interação entre usuários, envio de arquivos, textos online e coletivos e possibilita a avaliação por meio de questionários com questões de múltipla escolha ou discursivas. 
O colégio dispõe de um Núcleo de Educação a Distância, denominado de NEaD, que gerencia o Ambiente de Integração e promove a elaboração e o desenvolvimento de cursos locais na modalidade $\mathrm{EaD}$, para estudantes e educadores, e incentiva, dinamiza e monitora a participação nos cursos oferecidos pela Rede Marista. No Ambiente de Integração, foram criados vários espaços virtuais, agrupados em categorias diferentes, para atender às necessidades da comunidade escolar.

Ao acessar esse ambiente, foi possível perceber a oferta de vários serviços, incluindo agendas diárias, mural virtual e espaço virtual por série/disciplina/professor etc. Porém o foco dessa apreciação foi a categoria destinada aos discentes, intitulada "Cursos Virtuais": a) Produção Literária, idealizado para motivar a produção textual dos estudantes; b) História e Cultura Afro-brasileira e Indígena, oferecido aos estudantes do $7^{\circ}$ ano do ensino fundamental, como complementação de aprendizagem; e c) Matemática Básica, oferecido aos educandos do ensino médio, com conteúdos de revisão, cujo objetivo é de melhorar o aproveitamento e elevar os resultados na área de Matemática.

Para fins desta pesquisa, elegeu-se o Curso de História e Cultura Afro-brasileira e Indígena, oferecido aos estudantes do $7^{\circ}$ ano do Ensino Fundamental, na modalidade de EaD, como complementação da aprendizagem, observando os requisitos da Lei $n^{\circ}$ 11.645/08, que tornou obrigatório o estudo da história e da cultura afro-brasileira e indígena, nas escolas públicas e privadas de Ensino Fundamental e Médio no Brasil.

Esse curso e seus conteúdos levaram os estudantes a conhecerem a cultura, a história, os modos de vida e trabalho dos povos africanos e indígenas, bem como a situação atual em relação à formação da sociedade brasileira. Acredita-se que estudar a história e a cultura dos afrodescendentes e dos indígenas, considerando sua riqueza e sua contribuição, é um modo de repensar a identidade nacional e de rever a postura, as atitudes e os valores, por entender que esses povos foram, são e serão formadores da sociedade brasileira.

6.2 Com a palavra, os estudantes do $7^{\circ}$ ano do ensino fundamental

\subsubsection{O Ambiente Virtual de Aprendizagem (AVA)}

O Ambiente Virtual de Aprendizagem (AVA) é uma sala de aula virtual, que, disponibilizada na internet, agrega ferramentas para a criação, a tutoria e a gestão das atividades pedagógicas que materializam os cursos na modalidade de EAD. Seu objetivo principal é de promover a interatividade, viabilizando a construção do conhecimento, por 
meio de práticas de simulações, cooperação, hipertextualidade, construções coletivas e compartilhamento (SILVA, 2013). Para cumprir sua finalidade, esse ambiente precisa ser voltado para o público-alvo do curso, visando atraí-lo e mobilizá-lo. Nesse aspecto, o AVA do Curso de História e Cultura Afro-brasileira e Indígena do Colégio Marista Pio X cumpriu sua finalidade, pois, como mostra o Gráfico 1, 44\% dos estudantes pesquisados consideraram o AVA muito adequado, e 48\%, adequado ao desenvolvimento do curso.

Gráfico 1: Grau de satisfação dos estudantes com o AVA

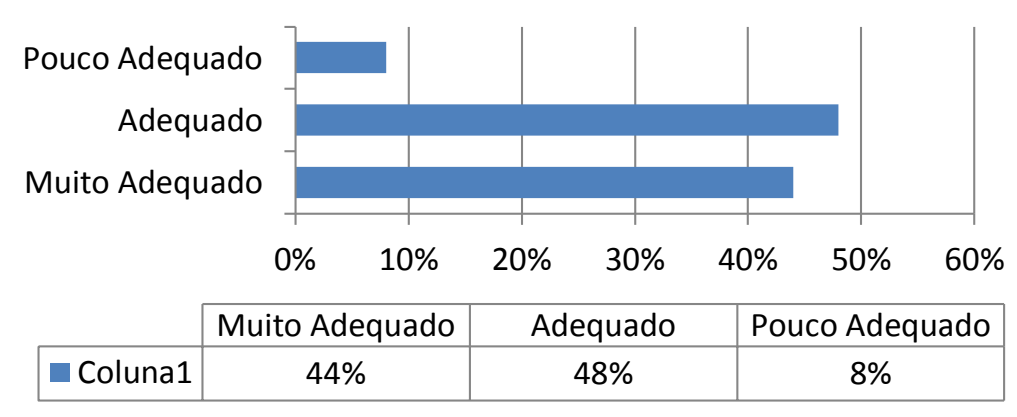

Fonte: Elaboração própria

A elevada satisfação com o AVA refletiu na adesão dos estudantes ao processo proposto no percurso didático-metodológico do curso, uma vez que eles avaliaram o grau de participação e de envolvimento de seus colegas como adequado, conforme ilustra o Gráfico 2. Segundo Dias e Leite (2012), não se cria uma sala virtual, mas se tenta criar uma escola virtual, pois, quanto mais completo, do ponto de vista pedagógico e não apenas do visual, for o AVA, será mais atraente e capaz de fazer a diferença no desenvolvimento dos estudantes.

Gráfico 2: Participação e envolvimento

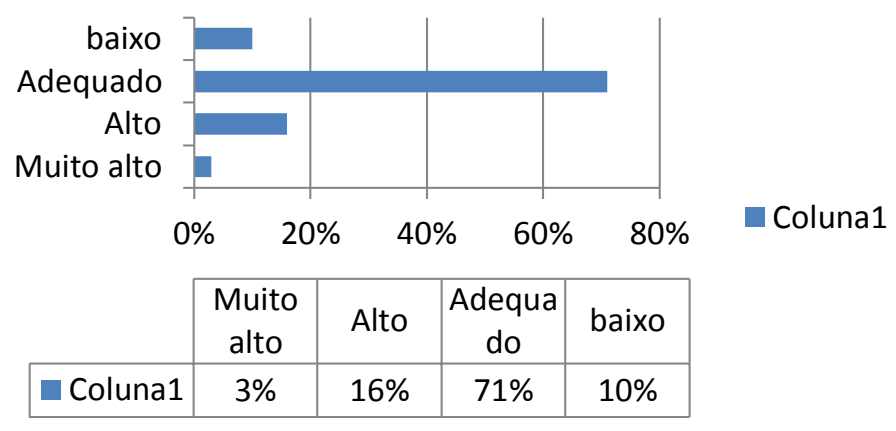

Fonte: Elaboração própria

Esse grau elevado do envolvimento e da participação dos estudantes é ampliado com os dados revelados nos Gráficos $3 a$ e 3b, que tratam da frequência e da permanência de acesso 


\title{
\#tear
}

ao AVA. Eles mostram que os estudantes mantinham uma rotina de acesso disciplinada e significativa e que a maioria dedicava um tempo considerável aos estudos e à realização das atividades, porque, em muitos casos, esse período longo não é mantido com as tradicionais tarefas de casa perpetradas nos livros e nos cadernos.

Gráfico 3a: Frequência de acesso

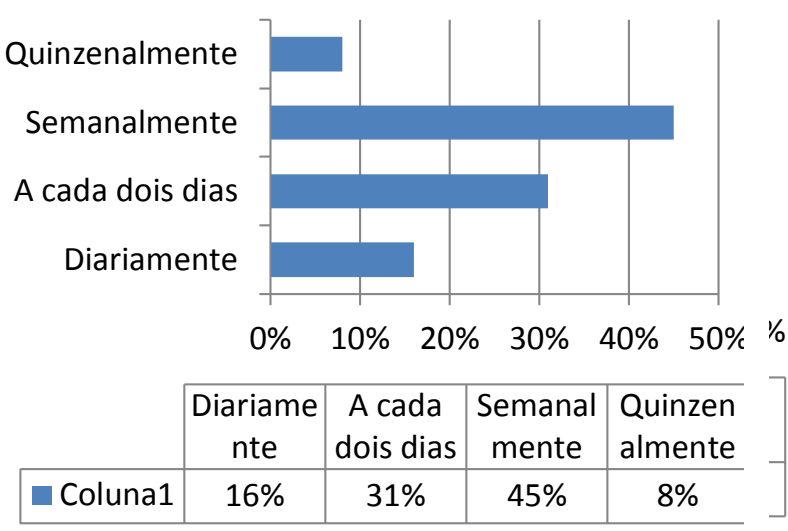

Gráfico 3b: Permanência

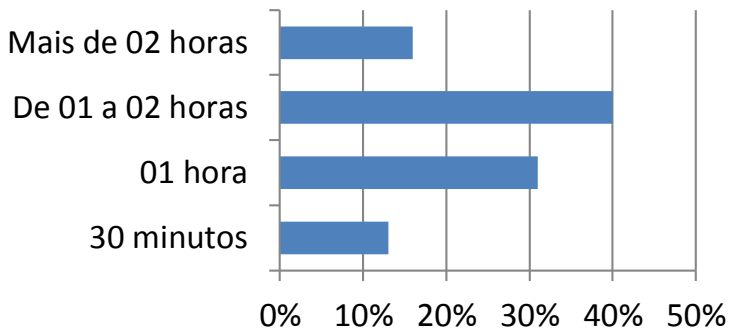

\begin{tabular}{|c|c|c|c|c|}
\cline { 2 - 5 } \multicolumn{1}{c|}{} & $\begin{array}{c}30 \\
\text { minutos }\end{array}$ & 01 hora & $\begin{array}{c}\text { De } 01 \text { a } \\
02 \text { horas }\end{array}$ & $\begin{array}{c}\text { Mais de } \\
\text { 02 horas }\end{array}$ \\
\hline Coluna1 & $13 \%$ & $31 \%$ & $40 \%$ & $16 \%$ \\
\hline
\end{tabular}

Fonte: Elaboração própria

Essa situação indica que a EAD pode ser uma alternativa de ampliação das competências, das habilidades e das atitudes na educação básica da geração dos nativos digitais, uma vez que a cibercultura é uma realidade em que são constituintes e constituídos ao mesmo tempo. Para Lévy (2010, p.174),

\begin{abstract}
a grande questão da cibercultura, tanto no plano de redução dos custos como no do acesso de todos à educação, não é tanto a passagem do presencial à distancia, nem do escrito e do oral tradicionais à multimídia. É a transição de uma educação e uma formação estritamente institucionalizadas para uma situação de troca generalizada dos saberes, o ensino da sociedade por ela mesma, de reconhecimento autogerenciado, móvel e contextual das competências.
\end{abstract}

No que diz respeito aos dispositivos usados para a realização do referido curso, ainda prevaleceu o notebook, seguido do computador de mesa, conforme demonstra o Gráfico 4. Ao serem perguntados sobre a necessidade de imprimir os materiais didáticos para as leituras e as atividades do curso, $95 \%$ afirmaram que não, e apenas 5\%, que sim. Entre as justificativas dos 95\% que responderam negativamente, um grupo destacou que prefere o meio digital ao texto impresso, outro grupo alegou que lia no celular, durante o trajeto de volta do colégio para casa, e outros declararam que os textos eram práticos, dinâmicos e podiam ser abertos de qualquer lugar, em qualquer momento, por isso dispensavam a impressão. Já os 5\% que afirmaram imprimir o material, destacaram a atividade de entrevista que precisaram realizar 
como a responsável pela necessidade de imprimir o material.

Esses dados mostram as mudanças paradigmáticas da atualidade e o conjunto de possibilidades e de novos valores que as tecnologias de informação e comunicação, aliadas à internet, inauguram entre as gerações. Segundo Castells (2003, p.167), "a virtualidade é nossa realidade. É isso que caracteriza a cultura na Era da Informação: é, principalmente, através da virtualidade que processamos nossa criação de significado".

Gráfico 4: Dispositivos usados

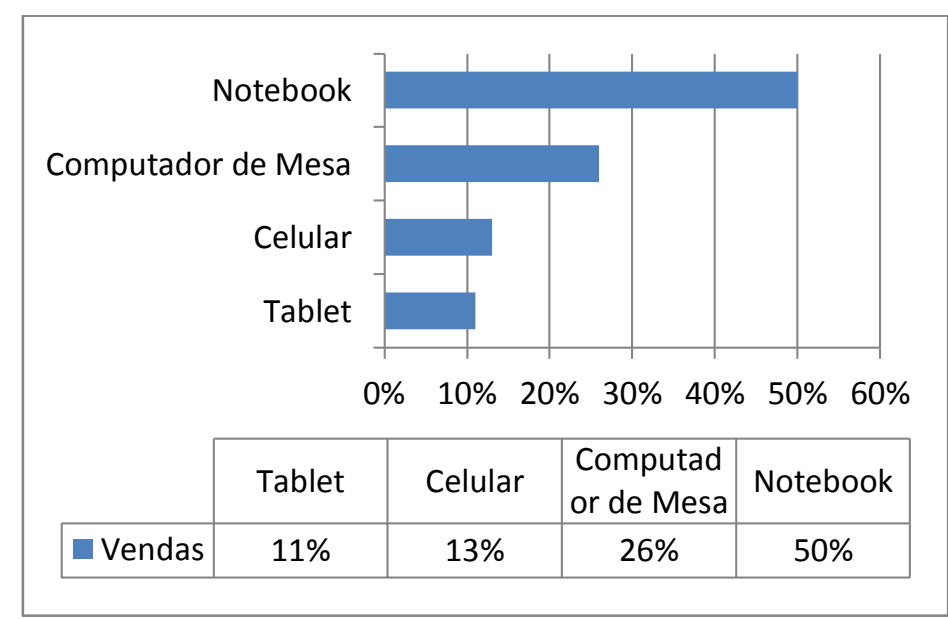

Fonte: Elaboração própria

A interpretação desse fenômeno não passa pela definição polarizada do que é bom ou ruim, mas de compreender as condições em que acontece, uma vez que a "sociedade encontra-se condicionada por suas técnicas" (LÉVY, 2010, p. 25). Em se tratando do condicionamento tecnológico, deve ser encarado como uma ampliação de possibilidades, subordinado a interpretações coletivas de âmbitos diferentes. Todavia, "não se trata de avaliar seus impactos, mas de situar as irreversibilidades às quais um de seus usos nos levaria a formular os projetos que explorariam as virtualidades que ela transporta e de decidir o que fazer dela" (LÉVY, 2010, p.26).

Os dados da pesquisa indicaram, também, que $85 \%$ dos estudantes não encontraram dificuldades para acessar o AVA do Curso de História e Cultura Afro-brasileira e Indígena, enquanto $15 \%$ tiveram problemas com o acesso. Os problemas sinalizados dizem respeito a alguns momentos em que o portal do colégio estava em manutenção, outros, em que o AVA não abria e/ou travava no celular ou, até mesmo, no computador; e outros registraram que a disponibilidade de computadores na biblioteca do colégio era insuficiente para esse fim. 


\subsubsection{As práticas pedagógicas}

Uma das dimensões constitutivas da EaD é a prática educativa (MAROTO, 1996), isto é, a materialização do processo educativo por meio de práticas pedagógicas fundadas por um conjunto de interfaces entre conteúdo e comunicação. As interfaces de conteúdo possibilitam a produção e o compartilhamento de materiais digitalizados em formatos e linguagens diferentes, e a interface de comunicação diz respeito à interação e à interatividade dos aprendentes. $\mathrm{Na} \mathrm{EaD}$, conteúdo e comunicação são elementos híbridos que instituem uma teia de sentidos e significados dialógicos que possibilitam a aprendizagem, uma vez que o conteúdo não é apenas informação ou material didático, e a comunicação não se reduz à utilização de dispositivos eletrônicos e digitas (SILVA, 2010).

Dias e Leite (2012) entendem que não é o espaço físico ou virtual que, per si, gera a aprendizagem, mas a dinâmica das práticas pedagógicas desencadeadas que configuram diferentes concepções de ensino-aprendizagem. Nesse horizonte, Silva (2010) afirma que a organização dessas práticas diz respeito à construção de um desenho didático a partir do planejamento, da produção e da operatividade de conteúdos e de situações de aprendizagem geradoras dos processos de conhecimento. Para esses autores, esse desenho didático, concebido como rede, e não, como rota, deve arquitetar percursos em teia de conexão com diferentes caminhos de aprendizagens; precisa disponibilizar uma montagem de conexões que permita múltiplas ocorrências, ao mesmo tempo em que se traduza em um ambiente intuitivo, funcional, de fácil navegação, um espaço aberto em favor da autonomia; e, por fim, ser um desenho didático capaz de provocar situações de inquietação criadora.

Em se tratando dos conteúdos do Curso de História e Cultura Afro-brasileira e Indígena oferecido pelo Colégio Marista Pio X, na modalidade de $\mathrm{EaD}$, a pesquisa mostra que os estudantes afirmaram unanimemente que os conteúdos foram elaborados de forma clara e compreensível, promoveram a autonomia nos estudos, e a organização do curso em módulos ajudou no desempenho. Sinalizaram, ainda, que os conteúdos apresentavam relevância e relação com o mundo e com saberes de outras disciplinas que estudam.

Se, de um lado, esses dados indicam que os conteúdos preparados contemplaram o potencial pedagógico, comunicacional e tecnológico do computador online (SILVA, 2010) e, por isso, foram bem recebidos pelos estudantes, de outro, ao serem analisados no contexto do AVA do curso, indicam certa centralidade no docente e no ensino, e não, na aprendizagem, conforme refere Sancho (2010), que justifica que isso acontece quando o estudante ocupa a 
maior parte do tempo estudando o material elaborado pelo professor, e a comunicação é controlada pelo tutor, que recebe a maior parte das mensagens e das consultas.

Para interagir com o conteúdo, os estudantes realizaram atividades de leitura, interpretação e produção textual, por meio de pesquisa, análise de imagens e documentários em vídeo, produção de relatórios, realização de entrevista, resposta a questionários e participação em fóruns. De acordo com os estudantes, essas atividades incentivaram mais a cooperação do que a competição, com destaque para os fóruns. Essa riqueza de atividades de estudo, apontadas de maneira positiva, sinaliza que o desenho didático do curso, mesmo com resquícios do ensino centrado no docente, rompeu com a visão tradicional do virtual e assumiu as concepções emergentes da $\mathrm{EaD}$ (SANCHO, 2010), o que contempla "uma intencionalidade pedagógica que garante a educação online como obra aberta, plástica, fluida, hipertextual e interativa" (SILVA, 2010, p.219).

Algo relevante apontado pelos estudantes foi o fato de reconhecerem que as atividades realizadas incentivaram mais a cooperação do que a competição, pois os processos colaborativos são essenciais para a formação humana. Ao tratar da aprendizagem coletiva e do novo papel do professor, Lévy (2010) afirma que o ponto principal é a mudança qualitativa nos processos de aprendizagem, e a direção mais assertiva que traduz a perspectiva da inteligência coletiva no domínio educativo é a aprendizagem cooperativa. Não basta aprender, é preciso aprender a aprender "com", em rede, não apenas na rede de computadores conectados pela internet, mas também nas redes de relações estabelecidas em prol do conhecimento.

\subsubsection{Mediação e aprendizagens}

O processo educativo em EaD é mediatizado pelo uso das tecnologias digitais da informação e comunicação e mediado pela ação docente em diferentes perspectivas. Dias, Leite (2012) e Fichmann (2012) asseveram que existe certa indefinição do papel e das funções do professor na EAD, porquanto ele foi transformado em entidade coletiva, já que surgem outras tarefas necessárias, porém diferentes das que existem nos meios presenciais. Trata-se do autor que seleciona os conteúdos, o webroteirista que organiza o material, o artista gráfico que trabalha com a arte visual e final do texto/material, o programador e o tutor que acompanha os estudantes. É fato que o professor também se torna um aprendente, um orientador ou facilitador das interações. 
A tarefa histórica atribuída ao professor de propagador de informações foi perdendo a razão de ser, quando os dispositivos tecnológicos e a internet tornaram o acesso à informação instantâneo, quase irrestrito e ilimitado. A competência docente "deve deslocar-se agora no sentido de incentivar a aprendizagem e o pensamento. O professor torna-se um animador da inteligência coletiva dos grupos que estão ao seu encargo" (LÉVY, 2010, p. 173). Não se trata de desvalorizar ou de diminuir o papel do professor, mas de conceber uma nova compreensão, no que diz respeito ao acompanhamento e à gestão das aprendizagens, bem como ao incentivo à troca de saberes e à mediação das relações.

Durante o Curso de História e Cultura Afro-brasileira e Indígena, 57,5\% dos estudantes que responderam à pesquisa disseram que foram acompanhados, que suas dúvidas foram esclarecidas que receberam retorno das atividades postadas no AVA, o que não aconteceu com 42,5\% deles. Entretanto, o nível de satisfação com a atuação do tutor, como demonstrado no Gráfico 5, é alto, o que indica uma contradição entre os respondentes, que, mesmo não se sentindo acompanhados, demonstraram satisfação com a atuação do tutor. Essa espécie de contradição pode sugerir a indefinição do papel docente na $\mathrm{EaD}$, conforme as considerações de Dias e Leite (2010).

Gráfico 5: Atuação do tutor

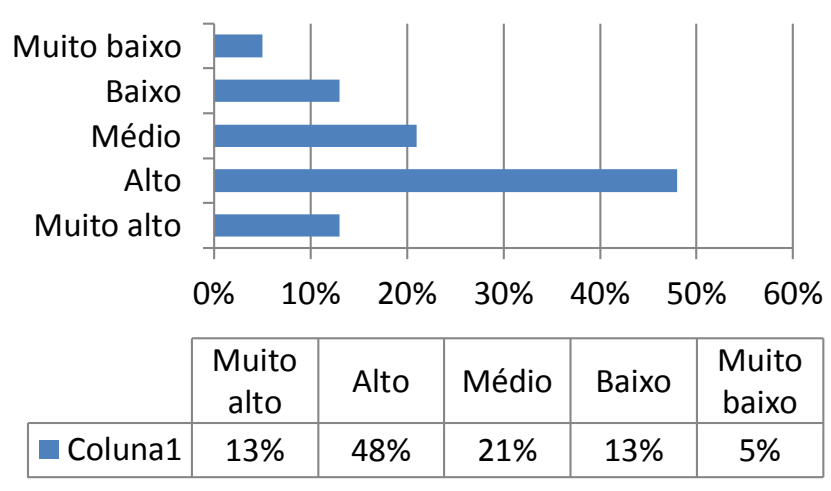

Fonte: Elaboração própria

De acordo com os dados da pesquisa, $95 \%$ dos estudantes afirmaram que aprenderam significativamente estudando em um AVA, e 5\% disseram que não. Essas informações corroboram o Gráfico 6, cujo teor demonstra que, de forma geral, o nível de satisfação dos estudantes com o Curso de História e Cultura Afro-brasileira e Indígena, oferecido na modalidade de EAD, foi elevado. 
Gráfico 6: Nível de satisfação dos estudantes

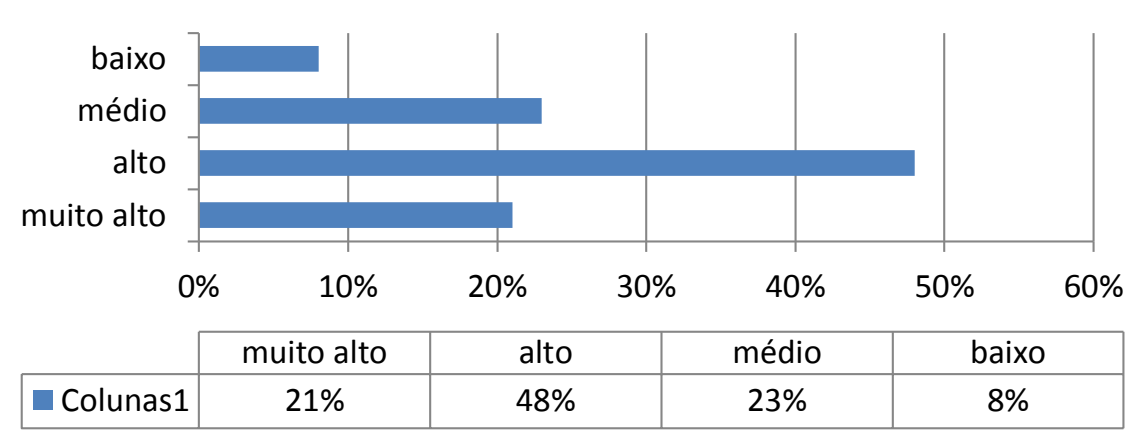

Fonte: Elaboração própria

Esses dados revelam a familiaridade dos nativos digitais com o ciberespaço e demonstram que as formas de aprender são múltiplas e variadas. Para Palfrey e Gasser (2011), aprender, hoje, é muito diferente do que era há 30 anos, porque a internet está mudando a maneira como as crianças, os adolescentes e os jovens coletam e processam as informações em suas vidas. A informação digital tem uma vida social nas mãos dos nativos digitais, pois seu compartilhamento é carregado de sentido e de valores que inspiram a construção das relações atuais. A acolhida, a seriedade e a satisfação que os estudantes do $7^{\circ}$ ano do Ensino Fundamental do Colégio Marista Pio X demonstraram ao participar dessa experiência reafirmam que fundamentos educativos e práticas pedagógicas tradicionais requerem mudanças urgentes, para que a escola do Século XXI consiga se ajustar às características e às condições da sociedade em rede.

Os estudantes também referiram que foi significativo conhecer outras culturas, aprender mais sobre outras religiões, sair da rotina de livros e cadernos, fazer atividades em casa, ter liberdade de organizar o tempo de estudo e o curso em módulos, selecionar os textos para estudo, responder as atividades com facilidade, aprender a utilizar mais o computador, comparar suas respostas com as dos colegas, além do fato de a pesquisa da cultura afrobrasileira e indígena ser incentivada. Também expressaram que desejam o fim do racismo e que o curso contribuiu para que se tornassem mais organizados. De maneira geral, destacaram como mais importante o curso ser a distância, a interação com os colegas e o documentário a que assistiram sobre a vida de Nelson Mandela.

Quanto ao de que não gostaram ou sentiram falta, os dados indicam a dificuldade com o AVA, que, algumas vezes, não abria; o atropelo do tempo para fazer as atividades de acordo com os prazos estabelecidos; o fato de o tutor não ser o mesmo professor de História da série; de construir as respostas das atividades e fazer uma entrevista e de encontrar as informações 
que desejavam e esclarecer dúvidas com rapidez. Eles sugeriram que o projeto contemplasse mais vídeos, tarefas em forma de jogos, atividades de estudo mais dinâmicas e design mais moderno da página, que as fontes de pesquisa fossem ampliadas, que tivessem mais prazo para realizar as tarefas, que o tutor ficasse mais tempo online para esclarecer dúvidas e que pudessem fazer todas as tarefas sem usar o word, pois sentiram dificuldades de utilizar o celular e o tablet.

Esses dados demonstram a qualidade das aprendizagens com a realização do curso a distância. As respostas claras e sólidas dos estudantes, no que diz respeito ao que foi significativo, e as dificuldades e as sugestões indicam que a experiência foi muito importante para os estudos. Em virtude disso, na contemporaneidade, talvez tenha chegado o momento de admitir que

o saber poderia ser novamente transmitido pelas 'coletividades humanas vivas' e não mais por suportes fornecidos por intérpretes ou sábios. O portador do saber não seria mais a comunidade física e sua memória, mas o ciberespaço, a região do mundo dos virtuais, por meio do qual as comunidades descobrem e constroem seus objetos e conhecem a si mesmas como coletivos inteligentes (LÉVY, 2010, p.166).

No jogo de sentido e na teia de envolvimento com que a ciência e a tecnologia enredam a história do tempo presente da sociedade em rede, nativos digitais e processos educativos parecem viver a "diáspora" de seu próprio tempo, no sentido de que um vai negando as condições existenciais e reais do outro, um emaranhado conflito entre a geração da cultura digital e a cultura da escola tradicional. Nesse contexto, fundamentos educacionais e processos pedagógicos já atinaram para o fato de que a escola do Século XXI está passando por uma transição que incide no papel, na missão, na socialização e nos desafios entre a difícil missão de ensinar e a necessária condição de aprender.

\section{Considerações finais}

A partir dos resultados da pesquisa, é possível afirmar que os estudantes do $7^{\circ}$ ano do Ensino Fundamental do Colégio Pio X conceberam a utilização da EaD como uma experiência positiva e apropriada. Trata-se de um processo que, quando bem arquitetado, agrega valor à sua formação, visto que possibilita a ação educativa no horizonte das redes de conhecimentos, aberta e em movimento, capaz de dialogar com os nativos digitais, na perspectiva da humanização, e não, apenas, numa espécie de fatalismo e de conformismo intermináveis. 


\title{
\#tear
}

A EaD ressignifica o tempo e o espaço porque rompe com os limites impostos por eles e possibilita um processo educativo centrado no estudante, considerando sua maneira de estudar e seu tempo de aprender. É certo que isso não acontece em oposição ou substituição à educação presencial, mas pode ser uma valorosa ampliação de possibilidades, e, talvez, uma alternativa para que as salas de aula não se tornem transitórias e descartáveis.

Embora os resultados alcançados na pesquisa tenham sido satisfatórios, é preciso investigar a percepção dos professores e das famílias sobre a $\mathrm{EaD}$ na educação básica e abordar o tema 'avaliação' nessa modalidade educativa. Como não se pretendeu esgotar o tema abordado, sugere-se que seja feita outra pesquisa, em que se dirijam diferentes olhares e se incluam outras temáticas, com o fim de confrontá-las com as práticas escolares e de contribuir para formar as gerações que estão por vir, diante da constante evolução tecnológica da sociedade em rede.

\section{CYBERLESSON AND DIGITAL NATIVES: A DISTANCE EDUCATION EXPERIENCE IN PRIMARY AND SECONDARY EDUCATION}

\begin{abstract}
The advent of digital information and communication technologies, combined with the use of the Internet, has provoked significant changes in contemporaneity, dimensioned by the characteristics of a network society, bringing new perspectives to Education. This study aims to analyze the perception of primary and secondary students (digital natives) in relation to the use of distance education as a complement to their learning in school. An explorative, quantqualitative research approach was taken with $7^{\text {th }}$ grade students enrolled, of School Marista Pio X, of João Pessoa, Paraíba, who participated in an Afro-Brazilian and Indigenous History and Culture distance course. Results indicate that the experience was significant for the students, when considering that it contributed successfully to the education process adopted by the school, as noted by the students' results and evaluation of the experience.
\end{abstract}

Keywords: Distance education. Primary and Secondary Education. Digital Natives.

\section{Referências}

ABED. Associação Brasileira de Educação a Distância, 2006. Disponível em: <http://www2.abed.org.br/faq,asp?Faq_ID=8>.-Acesso em: 16 jul. 2017.

ALVES, João Roberto Moreira. A história da EAD no Brasil. In: LITTO, Fredric Michael; FORMIGA, Manuel M. Maciel (Orgs.). Educação a Distância: o estado da arte. São Paulo: Pearson Education do Brasil, 2009.

ASSUMPÇÃO, Cristiana Mattos. O público infantil e juvenil e a EAD. In: LITTO, Fredric Michael; FORMIGA, Manuel M. Maciel (Orgs.). Educação a Distância: o estado da arte. São Paulo: Pearson Education do Brasil, 2012, v.2.

BARDIN, Laurence. Análise de Conteúdo. Lisboa: Edições 70, 2011. 
BIZZO, Nelio. O Ensino de Ciências e a EAD. In: LITTO, Fredric Michael; FORMIGA, Manuel M. Maciel (Orgs.). Educação a Distância: o estado da arte. São Paulo: Pearson Education do Brasil, 2009.

CARNEIRO, Moaci Alves. LDB fácil: leitura crítico-compreensiva, artigo a artigo. 23 ed. revista e ampliada. Petrópolis, RJ: Vozes, 2015.

CASTELLS, Manuel. A Galáxia da Internet: reflexões sobre a internet, os negócios e a sociedade. Rio de Janeiro: Zahar, 2003.

DIAS, Rosilâna Aparecida; LEITE, Lígia Silva. Educação a Distância: da legislação ao pedagógico. $3^{\text {a }}$. ed. Petrópolis, RJ: Vozes, 2012.

FICHMANN, Silvia. A educação formal básica/fundamental e a EAD. In: LITTO, Fredric Michael; FORMIGA, Manuel M. Maciel (Orgs.). Educação a Distância: o estado da arte. São Paulo: Pearson Education do Brasil, 2012.

GERHARDT, Tatiana Engel; SILVEIRA, Denise Tolfo. Métodos de Pesquisa. Porto Alegre: Editora da UFRGS, 2009.

GIL, Antônio Carlos. Métodos e Técnicas de Pesquisa Social. 6. ed. São Paulo: Atlas, 2014.

LÉVY, Pierre. Cibercultura. 3 ed. São Paulo: Editora 34, 2010.

LIBÂNEO, José Carlos et al. Educação Escolar: políticas, estrutura e organização. São Paulo: Cortez, 2009.

LÜCK, Heloísa. Gestão do Processo de Aprendizagem pelo Professor. Petrópolis - RJ: Vozes, 2014.

MAROTO, Maria L. Mata. Educação a Distância: Aspectos Conceituais. In: FORTE, M ${ }^{a}$ Cândida Mendes; LEITE, Selma Dias (Orgs.). Educação a Distância: alternativa para a construção da cidadania. Belém: Universidade Federal do Pará, 1996.

MUGNOL, Márcio. A Educação a Distância no Brasil: conceitos e fundamentos. Revista Diálogo Educacional. Curitiba, v. 9, n. 27, p. 335-349, maio/ago, 2009.

OLIVEIRA, Sidnei, Geração Y: o nascimento de uma nova versão de líderes. São Paulo: Integrare Editora, 2010.

OLIVEIRA, Daniel Figueiredo de. Sobre humanos e máquinas: marcos epistêmicos, ontológicos e éticos para compreensão do ciborgue e aprendizagem humana na cultura digital. Tese (Doutorado em Educação) - Universidade Federal da Paraíba, 2017.

PALFREY, John; GASSER, Urs. Nascidos na Era Digital: entendendo a primeira geração de Nativos Digitais. Porto Alegre; Artmed, 2011.

SANCHO, Juana M. Para Promover o debate sobre os ambientes virtuais de ensino e aprendizagem. In: SILVA, Marco; PESCE, Lucila; ZUIN, Antonio (Orgs.). Educação 
Online: cenário, formação e questões didático-metodológicas. Rio de Janeiro: Wak Editora, 2010 .

SÊGA, Christina Pedrazza. Sociedade e Interação: um estudo das diferentes formas de interagir. Brasília: Editora UnB, 2011.

SILVA, Marco. Desenho didático: contribuições para a pesquisa sobre formação de professores para docência online. In: SILVA, Marco; PESCE, Lucila; ZUIN, Antonio (Orgs.). Educação Online: cenário, formação e questões didático-metodológicas. Rio de Janeiro: Wak Editora, 2010.

SILVA, Robson Santos da. Gestão de EAD: Educação a Distância na Era Digital. São Paulo: Novatec, 2013.

SODRÉ, Muniz. Reinventando a Educação: diversidade, descolonização e redes. Petrópolis, RJ: Vozes, 2012. 